\title{
Climate Change Research and Credibility: Balancing Tensions Across Professional, Personal, and Public Domains
}

\author{
Stella Nordhagen ${ }^{*}, 1,2$, Dan Calverley ${ }^{2,3}$, Chris Foulds ${ }^{4}$, Laura Louise Thom ${ }^{2,3}$, \\ and Xinfang Wang ${ }^{2,3}$ \\ ${ }^{1}$ Queens' College, University of Cambridge, Cambridge, CB3 9ET, UK \\ ${ }^{2}$ Tyndall Centre for Climate Change Research \\ ${ }^{3}$ Sustainable Consumption Institute, School of Mechanical, Aerospace and Civil \\ Engineering, University of Manchester M13 9PL \\ ${ }^{4}$ Global Sustainability Institute, Anglia Ruskin University, Cambridge, CB1 1PT, UK \\ *Corresponding author: sn357@cam.ac.uk ; +22664549063
}

\begin{abstract}
For research to positively impact society, it must be scientifically credible. The researcher plays a key role in establishing and maintaining credibility, particularly in the climate change field. This paper provides a structure for relating the credibility of researchers themselves to that of research outputs, analysing 'researcher credibility' with reference to three overlapping domains: personal, professional, and public. The researcher's role in each domain is considered in a reflexive way, examining the research process and the researcher's actions. Varied definitions of researcher credibility and possible means to achieve it in each domain are discussed, drawing on relevant cross-disciplinary literature. We argue that, in certain contexts, the actions of researchers can have a direct impact on the credibility of their research. There is scope for broadening researcher credibility to include more public-oriented behaviours. This, however, may be contentious and problematic: there are potential conflicts between public action and professional credibility, with the latter usually taking precedence. By contrast, though personal action (or inaction) rarely affects professional credibility, researchers' personal behaviours may influence public perceptions of research credibility and the importance of addressing climate change.
\end{abstract}

Keywords: climate policy; personal activities; public engagement; research ethics. 


\section{Introduction}

Research's influence stems from both the knowledge presented and the process of knowledge creation (Mitchell et al., 2006), making examination of the research process essential for empowering science to respond to humanity's greatest challenges. For international environmental assessments to influence policymakers, they must be viewed as credible, salient, and legitimate (Mitchell et al. 2006). As such research outputs are produced by 'researchers', expert legitimacy is tripartite, involving knowledge, experts, and institutions through which they give advice, each requiring explicit attention. Past discussions have insufficiently emphasised the latter two (Jasanoff, 2005), leaving a gap in understandings scientific legitimacy and credibility.

Credibility is of particular consequence in climate change research, ${ }^{1}$ which is increasingly politicised and polarised in public fora, with the research community's collective reputation at stake. Illustrations include the UEA Climate Research Unit (CRU) email controversies (Gillis \& Kaufman, 2011; Maibach et al., 2012) and the dispute between scientist Peter Gleick and the 'climate-denialist' Heartland Institute (Goldenberg, 2012). There simultaneously remains a failure to effectively address the challenge framed by the research community (Black, 2011). Responsibility for this lies with both policymakers and researchers, as the scientific framing of climate change informs policymakers' understanding of its urgency. The research community thus finds itself at a critical juncture to reflexively examine the questions: what does it mean to be a credible climate change researcher and produce credible research outputs? This paper aims to stimulate and inform debate on this topic, as climate research's implications make it crucial to demarcate whether criticism is legitimate or not amidst intense politicisation (Keller, 2011).

Based on a wide, cross-disciplinary review of conceptions of credibility, we consider how the credibility of research outputs (hereafter 'scientific credibility', including social science) is related to that of researchers ('researcher credibility'). We present an analytical framework unpacking researcher credibility into three domains: personal, professional, and public. We then consider potential conflicts for researchers in maintaining credibility across these by drawing on diverse literature. ${ }^{2}$ Scientific and researcher credibility extend beyond the professional domain but are rarely assessed holistically and systematically. Researchers seldom openly discuss personal behaviour; when occurring, such discussions quickly become emotionally charged. This paper aims to stimulate structured discussion within and outside the academic community on researchers' professional, private, and public behaviours, as they impact scientific credibility. Its insights have relevance for broader discussions of credibility in multidisciplinary, controversial, and policy-relevant fields.

1 Including mitigation and adaptation work across physical, natural, and social sciences.

2 We focus on 'Western' research norms. 
To set-up fruitful discussion, the next section outlines key definitions, introducing a simple framework for viewing credibility. Sections 3-5 then delve into credibility within professional, public, and personal domains, respectively. Section 6 blurs these constructed boundaries to discuss tensions and trade-offs in maintaining credibility across all three before Section 7 synthesises conclusions.

\section{Key Concepts}

This paper is reflexive, examining the research process and researchers' actions/creeds. Reflexivity involves considering research conduct and how this moulds outputs (Holland, 1999), a process essential for scientists cultivating their trustworthiness (Wynne, 2006). Reflexive consideration extends to the researcher's network/communities (Hardy et al., 2001), and requires the researcher assess their impact on the object investigated. Therefore we will explore broader research practices, not just those associated with methodological/analytical decision-making. Some criticise reflexivity as difficult to assess (Seale, 1999), prioritising researcher over research (Finlay, 2002; Clegg \& Hardy, 1996), or impairing creativity (Weick, 1999). We thus cast reflexivity as a process for examining credibility.

Bocking (2004, p.164) defines scientific credibility as: 'the extent to which science is recognised as a source of reliable knowledge...[instead of] random observations, or...the preferences of a particular interest group'. Extending the concept to researchers themselves, we include both inward- and outward-facing elements, and credibility is recognised to be relational-between a researcher and an audience. Thus, concepts such as reliability, integrity, trustworthiness, and legitimacy, while applying to 'the science' itself, also help construct 'researcher credibility' through subjective judgements of researchers' peers, policy audience, friends, and the public. Outward-facing components can increase in weight as scientific debates filter through the media, who often scrutinise researchers as much as research.

Frequently, 'credibility' is used as shorthand for ideas of consensus, truth, and separating 'belief' from 'fact'. Consensus is an indicator of scientific credibility, revealing the scientific community's confidence level and positively impacting public belief in climate change and support for mitigation policies (Ding et al., 2011; McCright et al., 2013). However, attempts to establish the reliability of scientific claims solely by appealing to consensus are insufficient-several once-consensus models were later proven incorrect (Fraser, 2006; Russell, 1964). Further, there are limits to consensus amongst an interdisciplinary group; attempts to establish it may omit contrarian views, minimise uncertainties, and foster conservativity (Hulme \& Mahony, 2010; Oppenheimer et al., 2007; Hansen, 2007). Credibility must be viewed more broadly. 
Figure 1 thus illustrates our framework for analysing researcher credibility based on distinctions and interactions between three domains in which the researcher exists: professional, personal, and public.

\section{Figure 1. Domains of researcher credibility.}

US Academy of Sciences President Ralph Cicerone, referencing the CRU controversy, writes, 'the relationship between science and society depends on the personal conduct of scientists in all that they do' (Cicerone, 2010, p.624). Our definition of researcher credibility thus transcends the professional environment of academia, deriving also from public and personal domains. Sections 3-5 examine each in detail, emphasising achieving credibility beyond a solely professional audience and may motivate increased public engagement.

Beliefs about credibility vary within an interdisciplinary research community. This is partly determined by disciplinary paradigms, which include assumptions about epistemology (what one can know) and ontology (what exists). Beliefs associated with inquiry paradigms (e.g., positivism, founded in natural sciences, and constructivism, increasingly adopted by social scientists) largely shape what individuals within that particular 'expert community' count as credible research. (Cohen et al., 2007). Such differences inform definitions of professional credibility, leading to variations within climate change research, a diverse field. Valuations of 'truth' and 'knowledge' also vary culturally and temporally (Shapin, 1999). Researcher credibility is thus subjective and interpretive, influenced by context and 'epistemological roots'. With these caveats in mind, we proceed.

\section{Professional credibility}

Academia is largely self-regulating, driven by internal behavioural norms (Dasgupta, 2000). 'Truth' is achieved through constant challenge/debate, and a reputation for credibility is central to a successful career. An academic researcher gains professional credibility by obtaining academic qualifications and adhering to common research principles (e.g., 
Shavelson \& Towne, 2002) such as observing ethical standards (e.g., acknowledging funding, avoiding interest conflicts), publishing peer-reviewed research, methodological transparency and data availability (CSEPP, 2009).

These norms safeguard reputations of the individual and the academic research institution (Dasgupta, 2000); the ensuing practices are central to research careers (Hardy et al., 2001). 'Publish or perish' is the mantra of early-career researchers seeking advancement: professional credibility, which includes expertise and status, is commonly assessed by citation counts and publication analyses (e.g., Anderegg et al. 2010). Leadership of large projects (e.g., IPCC assessments) is oft-based on 'contributory expertise' (i.e. demonstrated competence in a specialist field, often measured partly by citations) (Collins \& Evans 2002, p.257).

Based on such principles, researchers gain professional credibility, which translates into influence within academia as newer researchers seek to enhance their credibility by aligning with pre-eminence (Latour, 1987). For example, Yohe \& Oppenheimer (2011) discuss how IPCC authors' judgements whilst constructing SRES emissions scenarios have shaped nearly every ensuing climate change impact/adaptation study due to the 'need to be anchored around one of the SRES storylines in large measure because they had the IPCC brand attached' (p.634). Funders with vested interests in outcomes (e.g., environmental research underwritten by environmental NGOs) may impact scientific credibility. If research appears compromised by sponsors' interests, the researchers' professional credibility will be cast into doubt. Conversely, research may gain scientific credibility if findings counter backers' interests. For example, the recent Berkeley climate-change meta-analysis, initially championed by 'climate sceptics', may have boosted climate science credibility when it yielded findings generally aligning with the consensus (BEST, 2011).

The Concordat, an agreement between funders and employers of UK researchers, posits six researcher responsibilities, including transferring and exploiting knowledge where appropriate to benefit employer, economy, and society (Research Concordat 2008). Thus, in addition to conducting the rigorous research required to build professional credibility, a researcher must ensure that research's credibility is upheld in the public domain, discussed next.

\section{Public credibility}

Maintaining credibility in the public domain raises questions of whether/how a researcher should engage publicly - including informing versus activism - and how engagement (or lack thereof) might affect professional and personal credibility and viceversa. The first two questions are addressed here; the latter will be considered in Section 6 .

'The public' is a construct (Wynne, 2006), here defined only as neither the academic community nor the researcher's close acquaintances. Given this heterogeneity, it is helpful to 
think of multiple 'publics', constituting different educational backgrounds, political ideologies, and cultural/social contexts (Blake, 1999; Leizerowitz et al. 2013) and manifesting various types of scepticism (e.g., 'attribution' versus 'science' sceptics; Painter, 2011). Knowledge will be interpreted differently as it travels amongst these audiences (Jasanoff, 1996, 2010; Blake, 1999), who may evaluate credibility differently (Mitchell et al., 2006). This heterogeneity complicates public engagement, as do complex cognitive factors involved in understanding climate change (e.g., Grothmann \& Patt, 2005), incomplete knowledge about public understanding of science (Shapin, 1999), and scientists' imperfect understanding of 'science in society' (Pielke, 2007). Keeping this heterogeneity and multiplicity in mind, for clarity we speak of credibility in the public domain.

Researchers are responsible for maintaining their work's scientific credibility in this public domain (Research Concordat, 2008). Research findings disseminated by media/political actors may be misrepresented; for example, media attempts to present 'balance' often exaggerate disagreement within the research community (Boykoff \& Boykoff, 2004; Painter, 2011), and there are numerous powerful interests involved in discrediting climate science (Oreskes \& Conway, 2010). This may contribute to low public confidence in climate change research. For example, opinion polls suggest sizeable portions of UK and US publics 'doubt' climate science (Carrington, 2011; Pew Center, 2009; Stafford, 2010; UPI, 2011), trust for climate science is much lower than trust in science (Scientific American, 2010), and citizens and government officials are generally less concerned than climate scientists (Weber, 2010). ${ }^{3}$

Given the strength of motivated reasoning against climate change and the intractability (and irrationality) of some individual's views (Hart \& Nisbet 2012), some segments of this demographic may be unreachable; it would be unfair to expect researchers to overcome such barriers. However, public engagement (research-related interaction outside one's personal/professional networks) may help counter the undermining of scientific credibility and reduce the likelihood of research misrepresentation. Interpreting the principle that research should be disclosed to encourage critique to apply outside the research community further encourages public engagement. 'Outreach' activities are often a condition of grants and academic contracts. Controversial, timely, or policy-relevant research is often covered by media, regardless of whether researchers wish to engage publicly. The reticent scientist may then need to engage to limit potential damage to scientific and professional credibility.

Public engagement to correct misinterpretations is widely encouraged as a scientific responsibility (Lackey, 2007); some encourage active political involvement (Keller, 2011). Yet the debate is neither novel nor one sided. Albert Einstein set himself against public engagement by scientists, stating that, it is the duty of a scientist to remain obscure' (Douglas 1996, p.100). The (heavily critiqued) 'linear model' of science policy sees 'basic' science as

3 As methodologies, samples, and question phrasings vary, findings should be treated cautiously. 
informing but removed from resulting policy (Pielke, 2007). Somerville (2010, p.513-4) allows a limited role for researchers to guide the public to recognise 'junk science', after which the public must, 'learn about what science has discovered and accept it'. In contrast, Jasanoff (2010, p.81) argues for a need to, 'enlarge the circles of accountability within which scientific judgment has to prove itself'.

Since people typically use information to confirm, not disprove, existing beliefs when dealing with ambiguities (Lord et al. 1979, in Patt \& Schröter, 2008), public confidence in climate change research will not likely increase without effort to ensure research findings are communicated clearly and unambiguously. The potential for dire ramifications and the beliefaction link give climate change researchers a unique responsibility to ensure their research's public credibility (Keller, 2011). Paul Nurse thus argues that 'scientists have got to get out there' to counter doubts over 'whether the public actually trusts scientists', including on global warming (Horizon, 2011). Public statements asserting professional consensus (e.g., 1700 British scientists declaring confidence in evidence for anthropogenic global warming; Price et al., 2009), are a generally uncontroversial move towards public engagement. Yet are such didactic statements sufficient? As 'informing' has not led to effective action by either policymakers or individuals, more proactive engagement may be required.

Comprehension/utilisation of knowledge could be encouraged via innovative communication methods (e.g., Marx et al., 2007; Lorenzoni \& Pidgeon, 2006). More controversially, researchers could directly interact with policymakers, for example, signing public letters for action, issuing policy opinions, or joining protests. Recent examples include Australian scientists petitioning Parliament and launching a publicity campaign to convince Australians they could rely on scientific evidence to inform decisions (Science \& Technology Australia, 2012) and scientist James Hansen, arrested outside the White House for protesting oil pipeline construction (Drajem, 2011). The 2012 'State of the Planet' Declaration, representing views of many sustainability researchers, argued forcefully for greater researcher involvement in policy-making (Brito \& Stafford Smith, 2012).

There is a difference between engaging on issues of science and those of policy; we must not conflate views of 'things done in the name of science' with views of science itself (Wynne, 2006, p.214). While scientific papers and grants commonly emphasise policyrelevance and include policy recommendations, these rarely translate into policy-making involvement. Indeed many argue this ought be avoided as potentially damaging to the scientist's professional and public credibility. For example, environmental journalist Andrew Freedman criticised Hansen's advocacy as, 'threaten[ing] to paint the AMS [American Meteorological Society] as having a political agenda' — a sentiment shared by some AMS members (Freedman, 2009; Revkin 2009a, 2009b). Physicist Freeman Dyson argued, 'Hansen has turned his science into ideology' (Dawidoff, 2009, p. 4).

Speaking about ecological policy, Lackey (2007) argues that while science is not value-free, this does not make all science normative and engagement by scientists ought be non-normative, explaining relevant findings but not advocating policy. The International 
Council for Science similarly encourages scientists to clearly separate professional from personal opinions (CFRS, 2010). Alternatively, Sarewitz (2004) argues scientists should generally avoid policymaking and, if engaging, should state their private interests and values. Pielke (2007) agrees that engaging on an issue like climate change can further politicise science, with scientists possibly becoming 'stealth advocates'. Yet he argues that instead of withdrawing, scientists should stay involved, acting as 'honest brokers of policy alternatives' who openly associate science with potential courses of action (Pielke, 2007). Others (e.g., Yohe \& Oppenheimer, 2011) argue that science communication should be done by communicators, not scientists.

There is thus no clear agreement on how to maintain public credibility, although most researchers would agree this is desirable. For this paper, we assume most climate change researchers regard climate change as a serious problem, believing action should be taken to mitigate its causes. Yet mitigation approaches vary in scale/scope, with widespread disagreement over whether leadership should be top-down (by governments, considering individual action effectively useless on its own) or bottom-up (collective/individual action as the only realistic solution, given political and economic barriers constraining governments). We next discuss whether maintaining credibility may necessitate action within one's own life - e.g., campaigning for top-down change or altering consumption habits and encouraging others to do likewise.

\section{Personal credibility}

Shapin (1999) argues modern life requires trusting experts to be well-intentioned; often credibility is inferred from character and truth established in personal, 'emotionally textured' domains (1999, p.10-11). Similarly, Lancet editor Richard Horton argues public trust connects to individual scientists' integrity (Shapin, 2004). While applying to researchers' conduct in each domain, integrity (adherence to moral/ethical principles, demonstrated through actions) and character have particular resonance within personal lives. The climate change researcher is in an unusual position: aspects of their personal behaviour (and associated carbon footprint) cannot be viewed in isolation from their professional expertise. Here we consider aspects of integrity and credibility in this personal domain.

In global and national terms, researchers in economically 'advanced' countries are typically financially privileged, with salaries falling considerably above median (IFS, 2011; ONS, 2010). This is significant as income is a decent proxy for emissions (Davis \& Caldeira, 2010). Researchers' education and almost-unparalleled access to state-of-the-science information arguably further obligates them to demonstrate integrity and credibility by mitigating their own emissions. Unfettered knowledge access is not universally available; academic journals are prohibitively expensive for individuals outside the system, and in many areas, internet access is restricted. While a layperson may not necessarily have the scientific literacy/information required to understand the mitigation challenge or how it can be met through practical action, the researcher can claim no such ignorance. Applying a combination 
of the 'polluter/consumer pays' and 'ability to pay' principles (Caney, 2010) thus arguably places a special obligation on Western researchers to mitigate their emissions, as both disproportionately responsible for emissions and best able (and informed) to make individual reductions. Yet researchers tend to have above-average carbon-intensive travel lifestyles, making it likely that they are amongst the largest individual emitters. (Høyer 2009) estimates international air travel emissions for a typical Norwegian climate change researcher as eight times the national mean.

However, in a diverse climate change research community, all researchers may not actively want to mitigate their emissions. Affluent and mobile, researchers tend to benefit from the status quo, which they may believe imposes no undue burden on future generations. If the researcher believes addressing climate change necessitates changing energy consumption, one can argue that specialist knowledge obliges them to be an agent of change. Simply imparting information to others is unlikely to produce change, however, due to the 'value-action' gap and motivated reasoning (Blake, 1999; Hulme, 2009; Sarewitz, 2010; Hart $\&$ Nisbet, 2011). Imparted information has impact when it captures the audience's attention, gains their involvement and overcomes potential scepticism (Stern, 1999). Personal motivational behaviour (e.g., peer pressure) may help influence behaviour change (Vermeir \& Verbeke, 2006). Researchers are well-positioned to influence their private networks by sharing relevant knowledge with family, friends, and communities on a personalised basis such relationships may offer considerable potential for influencing individual action (Leizerowitz et al., 2013). Leading by example (e.g., a 'sustainable' lifestyle), researchers may help shift underlying values, beliefs, and mistrusts. Conversely, the perceived hypocrisy of an informed but 'emissions-profligate' researcher could convince associates that change is neither required nor attainable. A climate change researcher who flies to distant destinations and drives a $4 \times 4$ thus damages their personal and public credibility and potentially that of the emissions-reduction message.

Amongst researchers, engaging with family, friends, and local communities on behavioural climate change issues is considered a personal decision dependent upon one's own ideologies and those manifesting in one's personal network. The decision to engage (or not) in individual leadership to maintain personal credibility may, however, impact public and professional credibility, as addressed next.

\section{Tensions in achieving 'holistic' credibility}

This artificial tripartite division of 'domains' was adopted to structure a discussion that can easily become muddled. In this section, we purposefully 'muddy the waters' to address the interesting (and hotly debated) tensions between these domains.

\section{Professional-Public Tensions}

As mentioned in Section Three, there is evident tension between professional and public domains: much of this, and much of the historic debate over scientists' public 
communication centres on the question of advocacy versus information. Many commentators (e.g., critics of Hansen's activism) have argued public activism undermines professional credibility; policy advocacy or campaigning harms the scientist's impartiality, providing fodder to climate change deniers and inviting them to impugn research validity. ${ }^{4}$ This can influence science: while empirical disagreements are typically negotiated through scientific journal papers and responses, this process is not necessarily value neutral — the harshest peerreview scrutineers are those with views opposing the author's (Sarewitz, 2004).

Some question the assumptions of the 'activism undermines credibility' argument. Jasanoff (1996), for example, argues scientists are embedded in a social context; scientific knowledge is co-produced by scientists and society and cannot be independent of political context. Many pragmatic scientists would agree. For example, in a 2006 survey of conservation biologists, the majority believed journals should publish research papers advocating policy preferences (Scott et al., 2007). An apolitical stance could arguably be an unrealistic 'ideal' in climate change research, since political decisions have large-scale consequences. Non-dogmatic political views, based on relevant science, are compatible with unbiased research and communication of findings. Yet criticisms of Hansen and other scientists engaged in advocacy show such opinions are far from universal.

Professional-public tension may be particularly acute for social scientists, for whom influencing behaviour may be an (implicit) research aim, with no clear line between 'information' and 'advocacy'. It may also challenge early-career researchers, seeking to establish themselves but also part of the generation expected to lead social change. Often drawn to climate change research by personal interest and belief in the necessity of curbing emissions, researchers may find themselves disagreeing with particular government actions/inactions and feel compelled to join public calls for stronger action. This contrasts with the common academic view that professional credibility demands researchers set aside their citizens' rights/responsibilities to hold the government accountable on their area of expertise.

This norm's strength is evidenced by how few researchers break ranks; dissenters are notable for their scarcity. One such researcher is American early-career glaciologist Jason Box. Arrested at the same demonstration as Hansen, Box defended his decision to protest by saying, 'I couldn't maintain my self-respect if I didn't go', not considering activism at odds with professional credibility (McGowan, 2011). By protesting, Hansen and Box made personal decisions, weighing the moral imperative to speak out against potential harms to their (and their institutions') professional standing. This could, by some arguments (e.g.,

4 This applies across the political divide: scholarship by 'climate sceptics' has also been criticised by non-'sceptical' academics for being influenced by the authors' political biases (Lewandowsky, 2011), and scientists with their own political loyalties and ideologies (backed by industry and political actors with financial resources and media acumen) have attacked and misrepresented research accepted by most of their peers (Oreskes \& Conway, 2010). 
Lackey, 2007), damage the overall scientific credibility of climate change research if researchers are seen as having an agenda. Yet one can also argue that while the researcher should not undermine scientific credibility of research, entering the profession does not annul their right to petition/protest: concern over 'credibility as a scientist' should not cause the scientist to 'disregard his credibility as a human being and voter with genuine convictions'. (Eipper 1970, p.35)

Keller (2011, p.19) suggests scientists should engage and would gain additional credibility by broadening allowable critics beyond intra-disciplinary peer review. Hansen (2007) similarly argues that 'scientific reticence' inhibits effective communication on climate change. However, engaging in this way could prove counterproductive if it drew attention to intra-academy disputes or highlighted professional behaviours vulnerable to criticism--e.g., frequent flights to conferences - and which potentially undermine public credibility of climate science. Yet hiding behaviours and disputes behind academic veils is unlikely to safeguard credibility - the IPCC Himalayan glacier error, for example, became more damaging to scientific credibility when not openly corrected and explained (Nature, 2010). Thus, work should be defended publicly only once established as scientifically credible through rigorous peer review.

\section{Professional-Personal Tensions}

In defending his activism, Jason Box alluded to how professional norms can be in tension with personal credibility. As discussed in Section Five, public action may be motivated by internal views of credibility ('self-respect') but constrained by the wish to preserve professional credibility. For example, a researcher may feel responsible to engage the public because of her specialist knowledge or because she thinks engaging only her personal network is inadequate. Weighing against these personal beliefs is the concern that public activism may harm professional credibility. Conversely, having to regularly attend conferences may be at odds with personal goals if it means leading a high-emissions work life. While an established academic may lose little 'sitting out' a conference if attendance would require air travel (e.g., Anderson in Hudson, 2012), the early-career researcher may miss a valuable opportunity to build their professional reputation/network. There are opportunity costs associated with both attending and not.

Inverting the orthodoxy, an alternative analysis of the relationship between personal and professional credibility might argue that hypocritical personal behaviour (i.e. acting inconsistently with research implications) undermines scientific credibility of research. If reducing consumption-based emissions is a central message of the research community, then researchers' personal behaviours are legitimate subjects of scientific scrutiny. Thus, if a researcher's work posits that effective mitigation can be achieved through widespread behaviour changes, then their own un-modified consumption undermines that hypothesis. In this view, there is a logical inconsistency between researchers' scientific claims about the potential for mitigation through behaviour change and their abrogation of responsibility for modifying their own consumption. 
Alternatively, one could view the researcher's absent personal mitigation as highlighting the embeddedness of decisions in one's sociotechnical landscape: social norms are intricately related to fossil-carbon-reliant production/consumption systems (Shove, 2003). This perspective suggests a broader sociotechnical transformation is required to stimulate transition in practices. Such systemic changes would then steer high-emitting practices in less energy-intensive directions.

\section{Personal-Public Tensions}

Such conflicts between personal and professional credibility and the apparent hypocrisy revealed could also undermine wider scientific credibility of climate change research. Increasing public engagement compounds this tension; damaging public credibility becomes likelier as barriers between personal and public domains are removed and researchers' behaviours become more visible. Those entering the public sphere may face personal and professional ramifications, particularly when political actors actively seek to discredit researchers: atmospheric scientist Ben Santer's efforts defending himself against 'mudslinging' hampered both work productivity and personal relationships (Oreskes \& Conway, 2010), Michael Mann's 'hockey stick' graph engendered assaults on his integrity from ardent denialists (Mann, 2012), and several climate scientists were labelled 'criminals' by US Senator James Inhofe (Nature, 2010). Such direct attacks actively militate against credibility in the eyes of hardened climate change 'sceptics', with views deeply sown by powerful interests. This may place researchers in no-win situations: accused of hypocrisy for failing to 'practise what they preach' or dismissed as having a 'green agenda' when adapting their lifestyles to reflect research implications.

Arguably, some climate change research branches do not directly use mitigation claims; researchers in those areas would not fall foul of the abovementioned 'self-falsifying behavioural inconsistency trap'. While a researcher might claim it is possible to bring emissions down and agree top emitters must cut the most, they might not recognise themselves amongst this group or may recognise their membership of the high-emitting group but believe their needs are somehow special or that others can more easily make reductions on their behalf.

While these counter-arguments might sidestep the logical-inconsistency trap (i.e. the professional-personal conflict), they cannot disguise the appearance of hypocrisy (the personal-public conflict), likely to draw stern criticism from those outside the professional domain. Maintaining public credibility may well depend on researchers visibly demonstrating belief in the science, for example by personally mitigating emissions. Furthermore, the UK Research Concordat's instruction to, 'transfer and exploit knowledge ...' (2008, p.12), could be interpreted to mean that, with regard to mitigation, researchers are enjoined to lead by example. It may be difficult to credibly transfer knowledge about climate change mitigation to the public and policymakers otherwise. A similar sentiment is found in the 'State of the Planet' Declaration's enjoinder to researchers to 'show leadership at all levels' on sustainability issues (Brito \& Stafford-Smith, 2012, p.4). 
Achieving credibility across all three domains is thus challenging: the researcher may struggle between 'hypocritical detached scientist' and 'activist partisan'. Some aspects of credibility are out of a researcher's control, dependent on extraneous factors, others' actions, or the socio-political context. For example, media editors may polarise issues to increase sales, manifesting a wider social norm of seeking 'controversy', and misinformation can be rapidly and anonymously propagated on the internet. (Oreskes \& Conway, 2010). However, researchers still have considerable control over their own actions' bearing on personal, professional, and public credibility and must exercise decisions accordingly.

\section{Conclusions}

This paper has examined 'researcher credibility' in depth, considering epistemological foundations, manifestations in public, personal, and professional domains, and tensions arising from trying to simultaneously maintain credibility across all three. While credibility has rarely been assessed to include personal and public-facing behaviours, it was argued that such holistic interpretation has merit and there are numerous tensions between professional, public, and personal motivations and actions. In cases of conflict, however, professional credibility conventionally trumps personal or public-facing concerns.

Several authors cited herein have suggested ways to enhance credibility of researchers and their science, including: more transparent publication/comments procedures; openness about uncertainty; explicit separation of 'advocacy' from 'science' in publications; better public/media communications, including about peer review; wider research dissemination; and better science education. When policy debates are motivated by differences in values rather than science, researchers may seek to shift discourse onto these differences, preventing science from becoming a scapegoat (Lackey, 2007) or engage in 'value advocacy' by speaking about the values leading them to consider climate change an urgent threat (Fischhoff, 2007). Where debates hinge on framing differences, identifying these underlying assumptions can also facilitate more productive discussions. Such helpful efforts should be promoted; Maibach et al. (2012) highlight examples already underway. Yet more is needed. Adopting definitions of credibility encompassing public and private domains - e.g., including researchers' willingness to publicly recommend actions based on their findings or personally put these into practice - could help ameliorate climate scepticism.

Although individual actions are socially embedded and some aspects of a researcher's credibility are out of their control, individual actions remain crucially influential. Climate change researchers' present personal and professional behaviours may generally contribute more to the climate change problem than its solution - despite researchers' privileges putting them in prime position to personally mitigate. Better leadership by researchers, both personally and publicly, would help. Societal barriers between 'personal' and 'professional' selves have been increasingly perforated by technological changes, offering novel opportunities for public interaction. By honestly discussing their own challenges in achieving a 'green' lifestyle — or not — researchers may help sway sceptics. This would require a shift in 
values and practices within the research community, recognising that the divide between professional credibility and public/personal action is false and that personal actions can affect public views of scientific credibility.

Within academia, such discussions of personal behaviour (e.g., conference travel) should be welcomed, not hushed - only by acknowledging these tensions can the field learn to balance them. More broadly, discussions should focus on what individuals within each of the professional, public and personal domains expect of science and its researchers. These expectations shape how individuals define credibility, a fundamentally relative concept. There is thus no definitive end-point at which research can be deemed universally credible; with a fuller understanding of expectations, however, scope for mutual understanding will widen. This paper does not attempt to prescribe a solution but rather open a space for structured debate. It is difficult to present universal, generalisable best practices; each individual researcher must decide the role they will play - a Ph.D. in a climate-change-related subject neither forces adoption of a low-energy lifestyle nor annuls a citizen's right/ability to protest. We thus advocate opening the climate change credibility debate to proactively embrace its political, subjective, and multi-actor nature, with researchers reflecting on how they balance tensions between the three domains and what trade-offs they ultimately concede.

\section{Acknowledgements}

The initial discussions leading to this paper took place at the Tyndall Researchers' Network meeting at Newcastle University on $14^{\text {th }}$ September 2011, we thank those who made the meeting possible. Further thanks to Lauren Roffey and Caroline Stuiver, who participated in early discussions surrounding the paper. We also thank John Turnpenny, Martin Mahony, Maria Sharmina, Lauren Roffey, Kevin Anderson and members of the University of East Anglia 3S Reading Group for constructive and helpful comments on earlier drafts.

\section{References}

1. Anderegg, W. R. L., Prall, W.J., Harold, J. and Schneider, S.H, 2010. Expert credibility in climate change. Proc Natl Acad Sci, 107 (27):12107-12109.

2. BEST (Berkeley Earth Surface Temperature Project), 2011. $<$ http://berkeleyearth.org $>$ [Accessed 16.12.2011.]

3. Black, R., 2011. Climate talks end with late deal. BBC News. $<$ http://www.bbc.co.uk/news/science-environment-16124670 $>$ Accessed 16.12.2011

4. Blake, J., 1999. Overcoming the 'Value-Action Gap' in Environmental Policy. Local Env 4 (3):257-278.

5. Bocking, S., 2004. Nature's experts. Rutgers University Press, New Brunswick.

6. Boykoff, M.T. and Boykoff, J.M., 2004. Balance as bias: global warming and the US prestige press. Global Env Change, 14:125-136 
7. Brito, L. and M. Stafford Smith, 2012. State of the Planet Declaration. Planet Under Pressure Conference.

http://www.planetunderpressure2012.net/pdf/state_of_planet_declaration.pdf

8. Caney, S., 2010. Climate change and the duties of the advantaged. Crit Rev Intl Soc and Pol Phil, 13(1): 203-228.

9. Carrington, D., 2011. Public belief in climate change weathers storm, Guardian. $L$ [Accessed 16.12.2011.]

10. Cicerone, R. J. 2010. Ensuring Integrity in Science. Science 327: 624.

11. Committee on Freedom and Responsibility in the Conduct of Science (CFRS) of the ICSU, 2010. Science Communication. http://www.icsu.org/publications/cfrsstatements/science-communication/> [Accessed 16.12.2011].

12. Clegg, S., and Hardy, C., 1996. Representations. In: Clegg, S.R., Hardy, C. and Nord, W.R., (eds.) 1996. Handbook of organization studies. Sage, London, pp. 676-708.

13. Cohen, L., Manion, L. and Morrison, K., 2007. The nature of inquiry - Setting the field. In: Cohen, L., Manion, L. and Morrison, K., eds. 2007. Research Methods in Education, New York, Routledge, pp. 1-47.

14. Collins, H. and Evans, R., 2002. The Third Wave of Science Studies. Soc Stud Sci, 32 (2), pp. 235-96.

15. CSEPP (Committee on Science, Engineering, and Public Policy), 2009. Ensuring the integrity, accessibility, and stewardship of research data in the digital age.. National Academies Press, Washington, D.C

16. Dasgupta, P., 2000. Economic progress and the idea of social capital. In: Dasgupta, P. and Serageldin, I., (eds), 2000. Social capital: a multifaceted perspective. World Bank, Washington, DC.

17. Davis, S.J. and Caldeira, K., 2010. Consumption-based accounting of CO2 emissions. Proc Natl Acad Sci 107 (12): 5687-5692

18. Dawidoff, N. (2009) The Civil Heretic, New York Times. $<$ http://www.nytimes.com/2009/03/29/magazine/29Dyson-t.html?sq=Freeman \%20Dyson $>$ [Accessed 16.12.2011].

19. Douglas, A. V., 1996. Forty Minutes with Einstein. J Royal Astron Soc of Canada, 50: 99-102.

20. Drajem, M., 2011. NASA's Hansen Arrested Outside White House at Pipeline Protest. Bloomberg News, [http://www.bloomberg.com/news/2011-08-29/nasa-s-hansenarrested-outside-white-house-at-pipeline-protest.html [Accessed 16.12.2011]

21. Eipper, A.W., 1970. Pollution Problems, Resource Policy, and the Scientist. Science, 169 (3940):11-15.

22. Finlay, L., 2002. Negotiating the swamp. Qualitative Res, 2 (2): 209-230.

23. Fischhoff, B., 2007. Nonpersuasive communication about matters of greatest urgency: climate change. Environmental Science \& Technology, 1 (41):7205-7208.

24. Fraser, C.G., 2006. The Cosmos: A Historical Perspective. Greenwood Publishing, Westport

25. Freedman, A., 2009. Science Group Erred Giving Hansen Top Honor. Washington Post 
$<$ http://voices.washingtonpost.com/capitalweathergang/2009/01/it_normally does no t make.html $>$ [Accessed 02.03.2012].

26. Gillis, J. and Kaufman, L., 2011. New Trove of Stolen E-Mails from Climate Scientist is Released. The New York Times, http://www.nytimes.com/2011/11/23/science/earth/new-trove-of-stolen-e-mails-fromclimate-scientists-is-released.html $>$ [Accessed 31.03.2012].

27. Goldenberg, S., 2012. Climate scientist Peter Gleick admits he leaked Heartland Institute documents, The Guardian $\leq$ http://www.guardian.co.uk/environment/2012/feb/21/peter-gleick-admits-leakedheartland-institute-documents $>$ [Accessed 2.03.2012].

28. Hansen, J.E., 2007. Scientific Reticence and Sea Level Rise. Env Res Leters, 2.

29. Hardy, C., Phillips, N. and Clegg, S., 2001. Reflexivity in organization and management theory. Human Relations, 54 (5):531-560.

30. Hart, P.S., and Nisbet, E.C., 2012. Boomerang effects in science communication: how motivated reasoning and identity cues amplify opinion polarization about climate mitigation policies. Communication Research, 39 (6):701-723.

31. Holland, R., 1999. Reflexivity. Human Relations, 52 (4): 463 - 84.

32. Horizon: Science Under Attack, 2011. [TV Programme] BBC, BBC2, 24 January 2011.

33. Høyer, K.G., 2009. A Conference Tourist and his Confessions. Tourism and Hospitality Plan Dev, 6 (1) pp. 53-68.

34. Hudson, M. 2012. Offsetting under pressure. Nature Climate Change, 2 (307).

35. Hulme, M. and Mahony, M., 2010. Climate Change: What do we know about the IPCC? Prog Phys Geog, 34 (5), pp. 705-718.

36. Hulme, M., 2009. Why We Disagree About Climate Change. Cambridge University Press, Cambridge.

37. Institute for Fiscal Studies (IFS), 2011. Where do you fit in? _ [Accessed 31.03.2012].

38. Jasanoff, S., 2010. Climate Science: The World Is Its Jury. In: Transparency International, (ed.) 2010. Global Corruption Report: Climate Change. London: Routledge, pp. 79-86.

39. Jasanoff, S., 2005. Judgment Under Seige: The Three-Body Problem of Expert Legitimacy. In: Maasen, S. and Weingart, P., (eds.) 2005. Democratization of Expertise? Springer, Dordrecht. pp. 209-224.

40. Jasanoff, S., 1996. Beyond epistemology: relativism and engagement in the politics of science. Soc Stud Sci, 26 (2):393-418.

41. Keller, E. F., 2011. What are Climate Scientists to do? Spontaneous Generations: $J$ Hist Phil Sci, 5 (1):19-26.

42. Lackey, R.T., 2007. Science, scientists, and policy advocacy. Conserv Biol, 21(1), pp. 12-17.

43. Latour, B., 1987. Science in Action. Open University Press, Milton Keynes.

44. Lewandowsky, S., 2011. Climate change denial and the abuse of peer review, http://theconversation.edu.au/climate-change-denial-and-the-abuse-of-peer-review1552>, [Accessed 24.11.2011]. 
45. Lorenzoni, I. and Pidgeon, N.F., 2006. Public Views on Climate Change. Climatic Change, 77 (1-2), pp. 73-95.

46. Maibach, E., A. Leiserowitz, S. Cobb, M. Shank, K.M. Cobb and J. Gulledges. 2012. The legacy of climategate. WIRE's Climate Change.

47. Mann, M.E., 2012. The hockey stick and the climate wars. Columbia University Press, New York.

48. Marx, S.M., Weber, E.U., Orlovea, B.S., Leiserowitz, A., Krantz, D.H., Roncoli, C. and Phillips, J, 2007. Communication and mental processes. Global Env Change, $17: 47-58$.

49. McCright, A., Dunlap, R. and Xiao, C., 2013. Perceived scientific agreement and support for government action on climate change in the USA. Climatic Change, 119 (2):511-518.

50. McGowan, E. (2011) Climate scientist willing to face arrest at tar sands pipeline protest. The Guardian.

$<$ http://www.guardian.co.uk/environment/2011/aug/18/climate-scientist-tar-sandspipeline-protest/print> [Accessed 31 March 2012]

51. Mitchell, R.B., Clark, W.C., Cash, D.W, and Dickson, N.M., eds. 2006. Global Environmental Assessments: Information and Influence. The MIT Press, Cambridge. pp. 307-339.

52. Nature, 2010. Climate of Fear. Nature 464: 141. 2010.

53. Office for National Statistics (ONS). 2010. 2010 Annual Survey of Hours and Earnings [<http://www.ons.gov.uk/ons/rel/ashe/annual-survey-of-hours-andearnings/2010-results/stb-ashe-2010.pdf $>$ [Accessed 31.03.2012]

54. Oppenheimer, M., O’Neill, B.C., Webster, M. and Agrawala, S., 2007. The Limits of Consensus. Science, 317, pp. 1505-1506.

55. Oreskes, N. and Conway, E.M., 2010. Merchants of Doubt. Bloomsbury, London.

56. Painter, J., 2011. Poles Apart: the international reporting of climate scepticism. Reuters Institute for the Study of Journalism, Oxford University Press, Oxford

57. Patt, A. and Schröter, D., 2008. Perceptions of climate risk in Mozambique. Global Env Change, 18:458- 467.

58. Patt, A. and Weber, E., 2014. Perceptions and communication strategies for the many uncertainties relevant for climate policy WIREs Clim Change, 5, pp.219-232.

59. Pew Center, 2009. Fewer Americans See Solid Evidence of Global Warming; Modest Support for 'Cap and Trade' Policy. Pew Research Center opinion> [Accessed 16.12.2011]

60. Pielke, R.A., 2007. The Honest Broker. Cambridge University Press, Cambridge.

61. Price, A. et al., 2009. Statement from the UK science community, 10 December 2009. Met Office http://www.metoffice.gov.uk/news/releases/archive/2009/sciencecommunity-statement, [Accessed 16.12.2011]

62. Research Concordat, 2008. The Concordat to Support the Career Development of Researchers. $<$ http://www.vitae.ac.uk/policy-practice/505181/Concordat-to-Supportthe-Career-Development-of-Researchers.html $>$ [Accessed 31.03.2012] 
63. Revkin, A.C., 2009a. Weather Mavens Honor Climate Maven. New York Times http://dotearth.blogs.nytimes.com/2009/01/14/weather-mavens-honor-climate-

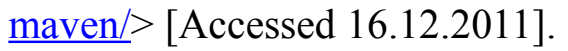

64. Revkin, A.C., 2009b. Hansen of NASA Arrested in Coal Country. New York Times http://dotearth.blogs.nytimes.com/2009/06/23/hansen-of-nasa-arrested-in-coalcountry/> [Accessed 16.12.2011].

65. Rowland, F.S., 1993. The Need for Scientific Communication with the Public. Science, 260 (5114) :1571-1576.

66. Russell, J.L., 1964. Kepler's Laws of Planetary Motion: 1609-1666. Brit J Hist Sci, 2 (1) pp. 1-24.

67. Sarewitz, D., 2004. How science makes environmental controversies worse. Env Sci Pol, 7:385-403.

68. Sarewitz, D., 2010. Science won't tell us what to do about climate change, but it can make the controversy worse. Slate Magazine.

$<$ http://www.slate.com/articles/health_and_science/green_room $/ 2010 / 03 /$ the trouble with_climate_science.html $>$ [Accessed 16.12.2011].

69. Science \& Technology Australia. Respect the Science.

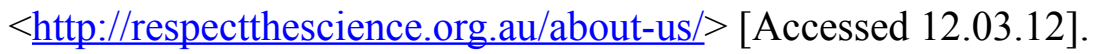

70. Scientific American, 2010. In Science We Trust. Scientific American $<$ http://www.scientificamerican.com/article.cfm?id=in-science-we-trust-poll $>$ [16.12.2011].

71. Scott, J. M., et al., 2007. Policy Advocacy in Science. Cons Biol, 21 (1): 29-35.

72. Shapin, Steven. 1999. Rarely Pure and Never Simple: Talking About Truth. Configurations, 7, pp.1-14.

73. Shapin, Steven. 2004. The way we trust now. In P. Hoodbhoy, D. Glaser, and S. Shapin, (eds.) Trust Me, I'm a Scientist. The British Council, London pp. 42-63.

74. Seale, C., 1999. Quality in quantitative research. Qualitative Inquiry, 5 (4): 465-478.

75. Shavelson, R. and Towne, L., 2002. Scientific Research in Education, Washington, D.C.: National Academies Press.

76. Shove, E., 2003. Comfort, cleanliness and convenience: the social organization of normality. Berg, Oxford.

77. Shove, E., 2010. Beyond the ABC: Climate change policy and theories of social change. Env Plan A, 42 (6):1273-1285.

78. Somerville, R.C.J., 2010. How much should the public know about climate science? Climatic Change: 509-514.

79. Stafford, N., 2010. Belief in climate change plunges. $<$ http [Accessed 16.12.2011].

80. Stern, P.C., 1999. Information, incentives, and pro-environmental consumer behaviour. J Consumer Policy, 22, pp. 461-478.

81. Vermeir, I. and Verbeke, W., 2006. Sustainable Food Consumption: Exploring the Consumer 'Attitude - Behavioural Intention' Gap. J Agr Env Ethics, 19 (2): 169-194.

82. Weber, E.U., 2006. Experience-Based And Description-Based Perceptions Of LongTerm Risk. Climatic Change, 77: 103-120.

83. Weber, E.U., 2010. What shapes perceptions of climate change? WIREs Climate Change, 2010: 332-342. 
84. Weick, K., 1999. Theory construction as disciplined reflexivity: Tradeoffs in the 90s. Acad Management Rev, 24: 797-806.

85. Wynne, B. 2006. Public Engagement as a Means of Restoring Public Trust in Science -Hitting the Notes, but Missing the Music? Community Genetics, 9: 211-220.

86. Yohe, G. and Oppenheimer, M., 2011. Evaluation, characterization, and communication of uncertainty by the intergovernmental panel on climate change - an introductory essay. Climatic Change, 108 (4): 629-639. 